\title{
Developing Strategic Cooperative Relationship in the Food Supply Chain: A Food Safety Perspective
}

\author{
Gang Liu *, Li Guo \\ School of Economy and Management, Tianjin Agricultural University, China \\ *Corresponding author: Gang Liu, PH.D, e-mail: liugang_tianjin@163.com
}

\begin{abstract}
Food safety is more and more concerned by consumers, developing strategic cooperative relationship in the food supply chain is an important tool for achieving food safety. The paper analyzes the reason for food safety issues from the perspective of relationship conflict in food supply chain, two sources of conflict have been identified: the attitude of members in food supply chain and power structure in food supply chain. For improving relationship quality in food supply chain and hence achieving food safety, the routes of relationship management are then proposed, arguing that relationship-specific investment, incentive payment and information sharing, these will be the key drivers of supply chain collaboration for food safety.
\end{abstract}

Key words: food safety; food supply chain; relationship management; relationship conflict; cooperation

\section{Introduction}

A supply chain can be defined as three or more organizations directly linked by one or more of the flows of products, services, finances, and information from a source to a customer. Supply chain management is a powerful tool to achieve collaboration among members in supply chain. Compared others, food supply chain is a more complex supply chain which including farmers, processors, wholesalers, retailers et al. Any problem in food supply chain will affect the entire food safety. The supplying of quality food depends on the interactions and cooperation between members in food supply chain.

\section{Brief literature review}

As the business environment becomes more complex, organizations recognize that many benefits can be obtained from closer, long-term relationships (S.Ganesan ${ }^{1}$ ). Firm performances can be maximized from establishing closer relationships with supply chain partners (K. F.Yuen and $V . V$. Thai ${ }^{2}$ ). Higher-quality supply chain relationships is characterized by the levels of trust, conflict, disengagement, and continuity expectations(S.D. Jap et $a l^{3}{ }^{3}$ ). It is necessary for partners to promote the level of channel coordination and information sharing to improve the overall supply chain performance (H.L. Lee et al. ${ }^{4}$ ). Some researchers suggest that agri-food supply chain coordination is a very important way for food safety(H. Yuanita et al. ${ }^{5}$ ). The moral hazard problem will affects the balance of benefits and costs in food supply chain, incentive payment-based approach is a useful way for improving food safety in supply chain. In food supply chain, traceability system is applied tool to assist 
in the assurance of food safety and quality as well as to achieve consumer confidence(M.M. Aung and Y.S. Chang ${ }^{6}$.

\section{Supply chain relationship conflict and food safety}

Why have food crises seemingly become more frequent in recent years? Relationship conflict in food supply chain is an important reason for food safety issues. Conflict has been suggested to interfere with team performance and reduce satisfaction because it produces tension, antagonism, and distracts team members from performing the task. Supply chain relationship conflict may be come from two aspects: the attitude of partners and the structure of channel power(M. Etgar ${ }^{7}$ ). We will analyze the relationship conflict in food supply chain based on the channel conflict model of Etgar, and explore the reason of food safety issues.

\subsection{The attitude of partners and food safety}

For consumers, food is typical credence goods which is difficult to know the real quality of food even after purchasing, whether farmers, processors, or others have strong opportunism motivation to take illegal production behavior. In food supply chain, moral responsibility is the key to food safety. In china, there have hundreds of millions of farmers and a great deal of production operators in food supply chain, the information about the quality of food is quite asymmetry between them because of high costs of monitoring. This brings moral hazard of illegal activities which leads to the problems of food safety. For example, farmers excessive using of pesticides or fertilizers, or processors illegal using of food additive.

\subsection{The structure of power in food supply chain}

According to the resource dependence theory, there have two kinds of power structure in food supply chain, including power imbalance and mutual dependence(T. Casciaro and M.J. Piskorski ${ }^{8}$ ). Power imbalance will make the weak side of supply chain increase the perception of opportunistic behavior from the strong side. Thereby the vulnerable are not willing to work together for the benefits of entire supply chain. In food supply chain, power imbalance may encourage large enterprises to take advantage to squeeze the interests of vulnerable groups. Thus leads to mutual deception in food supply chain, then cause the emergence of a series of food safety issues. For example, processors purchase the agricultural products from farmers at lower price deliberately, farmers provide shoddy agri-food for processors to safeguard their own interests.

\section{Supply chain relationship management modes for food safety}

The mutual trust among members in food supply chain is very critical for food safety. Supply chain relationship management can be used as an alternative to provide economically enforceable protection against opportunistic behavior. In food supply chain, solutions to the opportunistic behavior and food safety problems could include relationship-specific investments, incentive payment and information sharing (fig.1). 


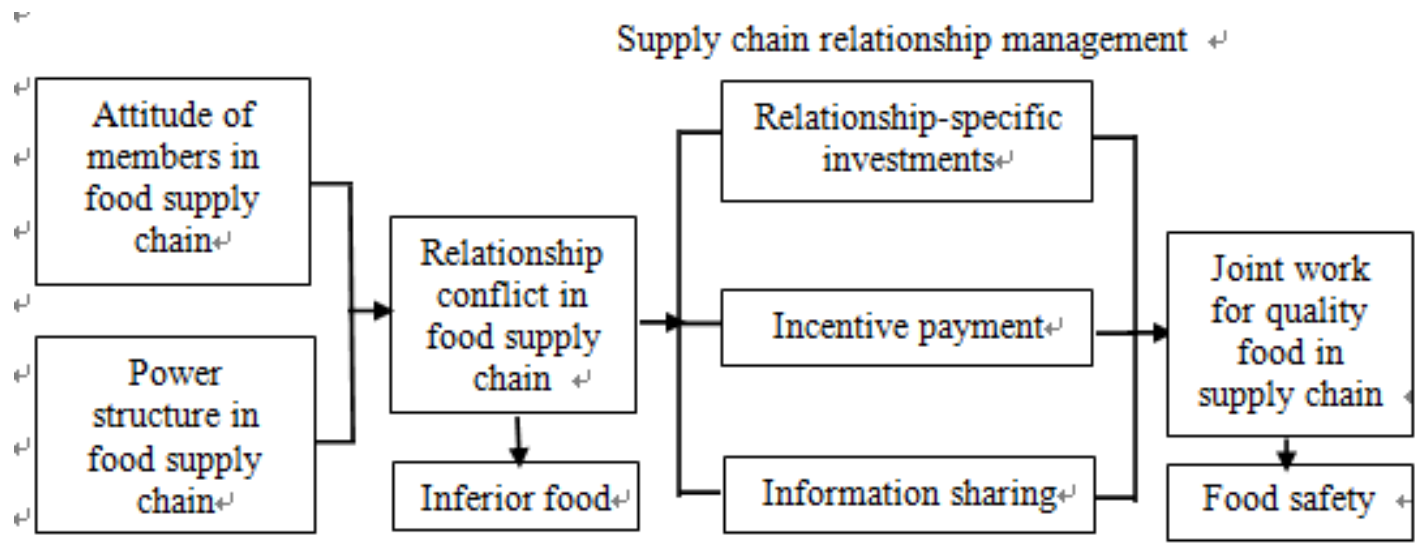

Fig.1- Supply chain relationship management modes for food safety

\subsection{Relationship-specific investments}

The specialization of asset is "a necessary condition for rent" and "strategic asset by their very nature are specialized”(R. Amit and P. Schomemaker $\left.{ }^{9}\right)$. A firm may choose to seek advantage by creating assets that are specialized in conjunction with the assets of alliance partner. In food supply chain, relationship-specific investments allow members to establish cooperative supply chain relationship, which reduces opportunistic behavior and mutual fraud, thereby enhancing food safety. Food safety achieved through relation-specific investments is derived from fewer defects between members, promising to partners and long-term transaction relationship. Relation-specific investments can be seen as a kind of pledge to build and sustain long-term trust. There have three types of asset specificity :(1) site specificity, (2) physical asset specificity, and (3) human asset specificity. In food supply chain, core enterprise can get trust from farmers or other partners through relationship-specific investments, encouraging farmers or other partners to work together for quality and safe food.

\subsection{Incentive payment}

Revenue sharing is the basic of cooperation in supply chain. Whether rational farmers or other operators will choose their behaviors to maximize their own interests. Several food-scandals indicate a gap between what actors do and what they are committed to do. Taking the poisonous milk powder as a case, uneven distribution of interests in food supply chain leads to illegal activities of farmers. In the face of the interests, someone had lost moral. Incentive payment is a useful tool to encourage partners to work together for quality food. Core corporation should design reasonable plan for income distribution in food supply chain, especially protecting the benefits of the disadvantaged. Incentive payment is conducive to the realization of the fair in food supply chain, and driving the right behavior of members in supply chain which is consistent with the common goal of food safety.

\subsection{Information sharing}

Chain members often have different private information, which is often not shared with others - thus asymmetric information is inherent in supply chains. For example, farmers have more information on pesticide residues compared with the processors or retailers. The processors have better information about food additives than retailers. Asymmetric information leads to hidden danger of food safety. Information Sharing is propitious to establish mutual trust in 
food supply chain. It requires making relevant, accurate and timely information available to all the decision-makers in food supply chain. On one hand, successive information communicating can minimize costs of entire supply chain by decreasing transaction costs, so as to increase the revenue of food supply chain, thus it is profitable for companies or farmers to produce safe and quality food. On the other hand, information sharing in food supply chain can facilitate the settlement with each other over the quality standard, quality control policies, benefit distribution.

\section{Conclusion}

Food supply chain managers face very different environments. Consumers' choices are increasingly being determined by requirements in the area of safety and health. Striving to safety and health is the new goal set by society, all members in food supply chain should set up the consciousness of responsibility and cooperate together in order to avoid producing inferior food. Therefore supply chain relationship management is becoming more important to achieve quality assurances for food. The routes of supply chain relationship management are then proposed, arguing that relationship-specific investments, incentive payment, information sharing, these will be the key drivers of supply chain collaboration for food safety.

\section{Acknowledgements}

This research was supported by the philosophy and social science planning project in Tianjin (Project No: TJGL15-038), and also supported by the innovation and entrepreneurship training program for college students in Tianjin(Project No: 201510061029), the People's Republic of China.

\section{References}

1. S.Ganesan, Determinants of long-term orientation in buyer-seller relationships, Journal of Marketing. 58(1994)1-19.

2. K.F. Yuen, V.V. Thai, The relationship between supply chain integration and operational performances: A study of priorities and synergies, Transportation Journal. 55 (2016)31-50.

3. S.D. Jap, C. Manolis, B.A. Weitz, Relationship quality and buyer-seller interactions in channels of distribution, Journal of Business Research. 46(1999) 303-313.

4. H.L. Lee, V. Padmanabhan, S. Whang. Information distortion in supply chain: the bullwhip effect, Management Science. 43(1997)546-558.

5. H. Yuanita, M.T. Togar, P. Tomy, Agri-food supply chain coordination: the state-of-the-art and recent developments, Logistics Research. 8 (2015)1-15.

6. M.M. Aung, Y.S. Chang, Traceability in a food supply chain: Safety and quality perspectives, Food Control.39(2014)172-184.

7. M. Etgar, Sources and types of intrachannel conflict, Journal of Retailing. 55 (1976)61-78.

8. T. Casciaro, M.J. Piskorski, Power imbalance, mutual dependence, and constraint absorption: A closer look at resource dependence theory, Administrative Science Quarterly. 50(2005)167-199. 
9. R.Amit, P.Schoemaker, Srategic assets and organizational rent, Strategic Management Journal. 14(1993)33-46. 